\title{
NOTA SOBRE XORIDES LATREILLE (ICHNEUMONIDAE, HYMENOPTERA) NO BRASIL 1
}

\author{
Vinalto Graf ${ }^{2}$
}

\begin{abstract}
Note on Xorides latreille (IChneumonidae) in Brazil. The Xoridinae with four genera are nearly cosmopolitan and Xorides are mainly Holartic in distribution. This genus has in South America three subgenera with four species, X. (Xorides) xanthisma Porter, 1975, X. (Pyramirhyssa) magnificus (Mocsáry, 1905), X. (Periceros) plumicornis (Smith, 1877) and X. (Periceros) euthrix Porter. 1975. The males of $X$. magnificus and $X$. xanthisma are described. Xorides euthrix and $X$. xanthisma are for the first time registered from Brazil. Comments are made on the morphology and distribution is registered for the eastern Brazil. Alphus sp. Cerambycidae, is the host of $X$. euthrix.

KEY WORDS. Ichneumonidae, Xorides, morphology, distribution, Brazil
\end{abstract}

A subfamilia Xoridinae tem quatro gêneros, três Holárticos e Xorides Latreille, 1809 de distribuição quase mundial. Este gênero, que forma um grupo natural fácil de reconhecer, com muitos subgêneros, conta com três subgêneros no Brasil: Xorides, com muitas espécies Holárticas, Periceros Schulz, 1906 e Pyramirhyssa Mocsáry, 1905, endêmicos da região Neotropical, muito raros nas coleções: "The species of Xorides tend to be so scarce in collections that it will be some time before they will be well enough collected to permit a definitive classification" (TOWNES 1960).

No catálogo dos ichneumonídeos neotropicais (TOWNES \& TOWNES 1966: 53) são citadas duas espécies de Xorides para o Brasil, X. (Periceros) plumicornis (Smith, 1877) do vale do Amazonas e Bahia e X. (Pyramirhyssa) magnificus (Mocsáry, 1905) de São Paulo.

PORTER (1975) descreveu, com detalhes, duas espécíes novas do nordeste da Argentina, $X$. (P. ) euthrix e $X$. (X.) xanthisma e redescreveu a fêmea de $X$. $(P$. ) magnificus. Na discussão Porter considera $X$. $(P$. ) euthrix muito semelhante a $X$. (P. ) plumicornis, mas com a comparação dos tipos e mais uma fêmea de plumicornis de Tingo Maria, Peru, apresentou uma série de diferenças entre as duas espécies; mas assim mesmo considerou a possibilidade de ambas serem raças da mesma espécie e que só com futuras coletas entre a "Selva Amazônica" e a "Selva Paranaense" poderia responder a esta questão.

Os espécimens de Xorides à disposição na Coleção Entomológica Pe. J.S. Moure do Departamento de Zoologia da Universidade Federal do Paraná foram

1) Contribuição número 823 do Departamento de Zoologia, Universidade Federal do Paraná.

2) Departamento de Zoologia, Universidade Federal do Paraná, Caixa Postal 19020.

81531-990 Curitiba, Paraná, Brasil. 
comparados com as descrições de PORTER e permitiram confirmar X. euthrix como uma boa espécie, além de ampliar a distribuição geográfica dessas espécies no sentido do leste do Brasil ao nordeste da Argentina, como já havia proposto PORTER para X. magnificus: "Although known previously only from São Paulo, Brasil, the presence of magnificus in northeast Argentina is not surprising. The Brasilian subtropical wet forest biome or Selva Paranaense (CABRERA \& WILLINK 1973, p. 60) reaches into Argentina across Misiones and in eastern Corrientes".

As espécies conhecidas da Argentina também foram coletadas principalmente no leste do Brasil (Espirito Santo: Santa Tereza e Conceição da Barra; Paraná: Fênix, Ponta Grossa, Curitiba e Piraquara; Santa Catarina: Nova Teutônia; Rio Grande do Sul: Pelotas e Santa Maria), havendo ainda poucos registros da bacia Amazônica, mas que demonstram que são espécies de ampla distribuição geográfica.

\section{Xorides (Xorides) Latreille, 1809 Xorides (Xorides) xanthisma Porter, 1975}

Xorides (Xorides) xanthisma Porter, 1975. Rev. Chilena Ent. 9: 55-56. Holótipo fềmea, Argentina, Misiones (Monte Carlo). Macho desconhecido.

Material examinado: BRASIL, Paraná: Piraquara, XI-1968, Pe. Moure leg., uma fềmea; Santa Catarina: Seara (Nova Teutônia), F. Plauman leg. VI-1972, duas fêmeas e dois machos, IX-1973, duas fêmeas.

Comentários. Comprimento das asas anteriores das fêmeas: 7,83-8,75mm; dos machos: 4,80 e $6,08 \mathrm{~mm}$. Os flagelos antenais com partes distais curvas em cotovelo, com três setas grandes, na curvatura.

Descrição do macho. Como a fêmea, com cabeça e tórax amarelos com manchas marrons, mas face amarela; fronte no meio marrom-amarelado; vértice desde os ocelos laterais até a carena ocipital e parte superior das genas marromenegrecido; primeiro tergito gástrico mais enegrecido e os seguintes marronenegrecidos a enegrecidos sem as faixas amarelas distais das fêmeas. Flagelo ferrugíneo-escurecido, sem anel amarelado, filiforme, reto e afinado para o ápice, com pêlos longos, eretos e esparsos, mais longos que o diâmetro dos flagelômeros. Em machos de $X$. euthrix e $X$. magnificus os pêlos do flagelo são mais curtos que o diâmetro dos flagelômeros. Primeiro tergito gástríco com as carenas médiodorsais até quase no ápice do tergito, as carenas dorso-laterais e médio-dorsais mais salientes e fortes que nas fêmeas; pós-pecíolo com comprimento 1,5 vezes sua largura apical.

\section{Xorides (Pyramirhyssa) Mocsáry, 1905 Xorides (Pyramirhyssa) magnificus (Mocsáry, 1905)}

Pyramirhyssa magnifica Mocsáry, 1905. Ann. Mus. Natl. Hungarici 3: 15. Tipo: fềmea, Brasıl, São Paulo.

Xorides (Pyramirhyssa) magnifica; H. Townes \& M. Townes, 1960. U. S. Nat. Mus. Bul. 216 (2): 530. 
Xorides (Pyramirhyssa) magnificus: Porter, 1975. Rev. Chilena Ent. 9: 52-53, Argentina, Corrientes: Las Marias, três fềmeas.

Macho desconhecido.

Material examinado. Brasil, Espírito Santo: Santa Tereza, 27-V-1964, C. Elias leg., uma fêmea; Paraná: Ponta Grossa (Lageado), XI-1944, Justus leg., uma fêmea; Santa Catarina: Seara (Nova Teutônia), XI-1970, F. Plaumann leg., um macho. Sem etiquetas de procedência, duas fêmeas.

Comentários. Comprimento das asas anteriores das fêmeas: 17,10-24,00 mm; do macho: 13,30mm. Flagelo das fêmeas com fraca curvatura distal e com seis a oito grande cerdas modificadas. As genas com fortes estrias oblíquas longitudinais que quase alcançam a parte superior onde continuam com pontuação grossa e densa nos lados do vértice; entre os ocelos laterais e os olhos compostos com estrias finas transversais. Na frente das estrias das genas, junto a órbita posterior, há uma larga faixa lisa e brilhante, que se estreita para o vértice. Em $X$. plumicornis e $X$. euthrix a faixa lisa junto a cada órbita posterior é muito estreita e as genas têm pontuação fina em $X$. euthrix e muito fina em $X$. plumicornis; e as estrias estão só na parte inferior das genas, junto às bases das mandíbulas. Em $X$. plumicornis o vértice é liso e brilhante com pontuação muito fina e esparsa, mais grossa em $X$. euthrix.

Descrição do macho. Como na fêmea, com cabeça, tórax e abdômen ferrugíneos, com muitas áreas amareladas; difere da fêmea no flagelo enegrecido, sem anel esbranquiçado, sem manchas amareladas no mesoscuto, nas axilas bem como nos tergitos gástricos, exceto uma pequena mancha no canto apical do primeiro tergito; a coxa posterior com manchas amareladas basais dorsal e ventral, menores que na fêmea; e o fêmur posterior sem manchas amarelas, com os extremos proximal e distal enegrecidos; tíbia posterior enegrecida com pouco mais que um terço distal amarela. Flagelo filiforme, afilado e sem modificações no ápice, com pêlos espaçados, eretos. O pós-pecíolo do primeiro tergito gástrico com comprimento 2,74 vezes sua largura distal.

\section{Xorides (Periceros) Schulz, 1906}

Perissocertus Smith, 1877. Proc. Zool. Soc. London, p.412. Nome pré-ocupado por Gerstacker. 1868.

Periceros Schulz. 1906. Spolia hymenopterologica, p.99. Novo nome.

\section{Xorides (Periceros) plumicornis (Smith, 1877)}

Perissocerus plumicomis Smith, 1877. Proc. Zool. Soc. London. p.412. Tipo: fêmea. Brasil: Vale Amazônico.

Periceros plumicornis; Schulz, 1906. Spolia hymenopterologica, p. 99, fêmea, Brasıl, Bahia: Orobó. Xorides (Periceros) plumicomis: H. Townes \& M. Townes, 1960. U.S. Natl. Mus. Bul. 216 (2): 501. - C. Porter, 1975. Rev. Chilena Ent. 9: 54, fềmea, PERU: Tingo Maria (Orillas del rio Huallaga). Macho desconhecido.

Material examinado. Brasil, Rondônia: Ouro Preto do Oeste, 3-X-1987. C. Elias leg., uma fêmea. 
Comentários. Comprimento da asa anterior: $14,00 \mathrm{~mm}$. Porter ao descrever $X$. euthrix considera a possibilidade de ser uma raça geográfica com $X$. plumicornis. As características que melhor diferenciam estas duas espécies são a epômia e a pubescência. Em $X$. plumicornis a epômia forma um lobo para trás fortemente oblíquo e a pubescência prateada é muito densa e longa nos lados da gena, escutelo, axilas, pronoto, mesopleura, metapleura e propódeo. As três áreas medianas (basal, aréola, pecíolo) do propódeo bem como primeiro tergito abdominal são lisos e brilhantes. Em $X$. euthrix a epômia é vertical e a pubescência é bem mais esparsa. As áreas basal e areolar do propódeo em geral não são separadas e apresentam rugas transversais, incompletas na parte basal, e o primeiro tergito abdominal apresenta fina rugosidade. Xorides plumicornis tem cabeça e tórax pretos, mas metapleura, mesosterno e parte posterior do propódeo um pouco tingidos de ferrugíneo; abdômen e pernas ferrugíneas, com as tíbias e tarsos amarelos ou amarelo-ferrugíneos, menos os distitarsos das pernas anteriores e médias enegrecidos; $X$. euthrix é ferrugínea, mas o tórax pode estar um pouco enegrecido dorsalmente e as tíbias posteriores com um sexto distal ferrugíneo em alguns espécimens.

As órbitas internas das duas espécies têm largas faixas branco-amareladas descle a região malar até o ocelo médio, em geral mais largas na face, inclusive o clípeo. As diferenças estruturais mostram que se trata de duas espécies bem distintas.

\section{Xorides (Periceros) euthrix Porter, 1975}

Xorides (Periceros) euthrix Porter, 1975. Rev. Chilena Ent. 9: 53-55. Holótipo fềmea, parátipos fềmeas e machos. Argentina, Misiones: San Javier; Corrientes: Las Marias; Misiones: Leandro Alem e Puerto Rico.

Material examinado: Brasil, Espírito Santo: Conceição da Barra, 25-IX1969, C. T. \& C. Elias leg., uma fêmea; Paraná: Fênix (Reserva Est. -ITCF), 29-XII-1986, 23-III-1987, Lev. Ent. PROFAUPAR, malaise, duas fêmeas; Curitiba (in lab), 10-X-1977, F. Giacomel leg., quatro fêmeas; Santa Catarina, Seara (Nova Teutônia), VII-1972, F. Plauman leg., um macho; Rio Grande do Sul: Rio Pardo, Bexiga, 22-XI-1955, A. Cordeiro leg., um macho; Santa Maria, 13-15-XII-1993, L. Witeck leg., dois machos; Pelotas, 11-II-1970, O. Mielke leg., uma fêmea. Sem etiquetas de procedência, duas fêmeas.

Comentários. Fêmea e macho não diferem da descrição de Porter. Comprimento das asas anteriores das fêmeas: $8,00-13,60 \mathrm{~mm}$; dos machos: 9,50-10,30mm.

Coloração. Ferrugínea com as tíbias e tarsos amarelos, mas com os tarsos anteriores, médios e metade distal dos distitarsos posteriores enegrecidos; tíbia posterior amarela, mas com a parte distal, em alguns espécimens, de coloração ferrugínea.

Biologia. Hospedeiro - Alphus sp., Cerambycidae, obtidos de troncos de mamica-de-cadela, Fagara sp., Rutaceae, coletados no Centro Politécnico da Universidade Federal do Paraná em Curitiba pelo Prof. F. Giacomel. 
AGRADECIMENTOS. O autor agradece à Profa. Danúncia Urban pela revisão dos originais e ao Prof. Fioravanti Giacomel pelos espécimens de X. euthrix e dos cerambicídeos Alphus sp. criados em laboratório.

\section{REFERÊNCIAS BIBLIOGRÁFICAS}

PORTER, C. C. 1975. Argentine Xorides (Hymenoptera:

Ichneumonidae). Rev. Chilena Ent. 9: 51-56.

Townes, H. K. 1969. The Genera of Ichneumonidae. Part 1. Mem. Amer. Ent. Inst. 11: 1-300.

TOWNES, H. K. \& M. TownEs. 1960. Ichneumon-Flies of America North of México: 2. Subfamilies Ephialtinae, Xoridinae, Acaenitinae. Bull. U. S. Natl. Mus. 216 (2): 1-676.

1966. A Catalogue and Reclassification of the Neotropic Ichneumonidae. Mem. Amer. Ent. Inst. 8: 1-367.

Recebido em 20.IX.1994; aceito em 08,II, 1995. 